\title{
Am I missing something by not using story-telling? Why we should ask university students to use story-telling to evaluate their experiences of learning
}

\section{Dr Gina Sherwood}

School of Education and Sociology, University of Portsmouth, UK For correspondence:

St George's Building, 141 High Street Portsmouth, PO1 2HY, UK Tel: 02392845235

Email: gina.sherwood@ port.ac.uk

\begin{abstract}
Evaluations of student's learning experiences hold increasing currency in deciding how to improve teaching and learning. This article proposes that students who use storytelling for evaluation help to facilitate this. Adding to previous research that shows the benefit and challenges of gathering qualitative feedback, stories written by 47 Childhood Studies undergraduate students while at university in England explain their learning experiences. Analysis of the content of their stories identified what their learning journey had been like providing useful information to shape teaching and support their wellbeing; both important measures for universities because they are factors that influence retention and the number of applicants to their institution. The research concludes that stories written by students are useful because they enable the $\mathrm{HE}$ teacher to engage in new ways of listening and responding to personal accounts that communicate what the learning experience is like for students and what is important to them.
\end{abstract}

\section{Keywords}

Teaching, student evaluation, story-telling, wellbeing, student experience 


\section{Introduction:}

This research explores how students who write stories about their learning experiences can inform teaching and understanding of the support that undergraduates need during their studies. Reflection that enhances teaching in Higher Education (HE) is essential to ensure that students who attend university leave confident and ready to share their knowledge and perspectives at the next stage of their lives. This rationale extends beyond student outcomes because the quality of their learning experience influences how they respond when completing the National Student Survey (NSS). The outcome of their evaluations dictates the ranking of universities and potentially the number of applications each year (Lenton, 2015, Callender, Ramsden and Griggs, 2014). This means that capturing and responding to student feedback has significant outcomes.

The research in this paper proposes a different way to elicit student views that complements the findings from summative questionnaires such as the NSS and the Student Evaluation of Teaching (SET) Surveys. Students who complete these evaluations can choose to add free-text comments, however, research recognises that the results are narrowly drawn and only cover certain aspects of their experience (Callender et al, 2014). I wanted to find out if students' stories about learning brought additional information to light.

Using stories to find out about learning experiences is not new, for example Flint, et al (2009) developed composite stories from free-text comments. This paper builds on their idea by applying story-telling to gain student feedback. The forty-seven participants in this research were childcare undergraduates at a university in England. The purpose was for students to communicate their views about the learning experience giving them a voice and style that was chosen by them. Bolton's (2014) findings showed how students' stories contained a blend of learning, personal feelings and experiences and I was eager to discover if this would happen in my research. Such knowledge would be valuable for helping me to discover more about the 
student's learning experiences and what is important to them. The purpose of sharing this practice is to suggest methods of gathering stories and how the interpretations can shape students' future learning experiences.

This paper explores the purposes of evaluations, reviews the responses of HE teachers to the feedback and then focuses on the content and outcomes of students who wrote their own stories. The discussion explains how this method of gaining student feedback can contribute new knowledge and understanding about undergraduates' experiences and therefore has the potential to improve practice in teaching and support.

\section{Background}

\section{The role of student evaluations}

Finding out about students' experiences of their learning in Higher Education is important to the HE teacher for a number of reasons, to improve and develop their teaching; to understand the current educational attainment and potential of their students; to support their wellbeing and for quality assurance and human resources purposes (Hoon et al., 2015; Meehan and Howells, 2018; Stein et al, 2013). The results are scrutinised and used to rate the standard of the university, something that has generated competition between universities since the removal of the student number cap (Lenton, 2015). The introduction of the Teaching Excellence Framework (TEF) in England in 2017 has added another measure, as universities are awarded a bronze, silver or gold according to teaching quality, student outcomes and the learning environment. The broader aim of the TEF is to ensure that potential students are better informed about the teaching within the institution they are applying for (Ashwin, 2017). So, finding ways to capture and respond to evaluation is considered significant to the university and for students particularly when it improves their learning experience. 
Currently summative student feedback is mainly captured via evaluation questionnaires such as the National Student Survey (NSS). This questionnaire that is distributed to final year undergraduate students in England as part of the Higher Education Funding Council for England's (HEFCE) Quality Assurance Framework. It applies specific questions about the teaching, content of the course, assessment and the learning environment. The student responds using a Likert scale with a range of satisfaction scores from strongly agree to strongly disagree. It is considered a robust, reliable and valid instrument that 'supports internal quality assurance processes' (Callender et al, 2014, 17). Students have the option to include free-flow comments to explain their chosen satisfaction rating. This qualitative feedback can add context and detail to the learning experience and is identified as both valuable and insightful (Curtin, 2013; Grebennikov and Shah, 2013; Symons, 2006).

During their undergraduate studies students are also asked to complete Student Evaluation of Teaching (SET) surveys at the end of modules and to rate each year of study. These apply the same structure as the NSS and are requested regularly which may influence the results as students experience consultation fatigue (Chan, Luk and Zeng, 2014). Nevertheless, the results of these surveys are reviewed by the HE teacher and are intended as a guide to improve the content, delivery and resources provided the following year.

Dunworth and Santiago Sanchez $(2016,3)$ conclude that evaluations are key in shaping practice going forward, by:

... helping to clarify good performance, facilitating reflection, encouraging dialogue about learning, promoting self-esteem and providing opportunities to close the gap between current and desired performance.

Potentially, the results have positive outcomes for the HE teacher and the student because quality feedback from students provides information that can be used to improve performance and increases the HE teacher's understanding (Dunworth and Santiago Sanchez, 2016; Flint et 
al, 2009). Golding and Adam (2016) add that listening to students is part of our duty to improve and take care of them, something undergraduates highlighted in the Student Experience Survey (THE, 2017). These explanations of the role of student feedback identify the importance of embracing a variety of ways to listen to individuals' views.

Winchester and Winchester (2014) advise that if evaluation is to have an impact it is essential to work with students as partners. Others agree that dialogue through partnership can build 'pedagogic intelligence' encouraging feedback on the effectiveness of teaching ( $O$ 'Donovan, et al 2008). In this context evaluation becomes an active procedure that Grebennikov and Shah (2013) describe as instrumental in shaping university priorities. In order to respond to this research it is important to find ways to build a partnership with students and then respond to their views.

Traditionally, students are invited to communicate using free-text comments and Hoon et al (2015) endorse opportunities for students to provide qualitative feedback in this way. They recommend that methods are developed to retain full expression and enable students to provide deeper information. However, not all students participate which is why Stein et al, (2013) recommend collecting feedback in a variety of ways. While the intention to gather students' views is clearly laudable, Khan (2013) found that some students were sceptical about whether their responses would make a difference. If students are expected to engage in communicating their learning experiences honestly the reactions and responses of the HE teacher also need to be scrutinised.

\section{HE teachers' responses to student evaluations}

HE teachers' responses to evaluation feedback has been the subject of research for many years (e.g. Arthur, 2009; Chan, Luk and Zeng, 2014; Golding and Adam, 2016; Stein et al, 2013 Surgenor, 2013, Winchester and Winchester, 2013). Participants have shared a variety of views, some focused negatively on results and the students who have completed them. 
Surgenor (2013) reports examples of HE teachers who argued that students are unqualified to make a judgement and therefore their views are not valid, especially if they have not engaged in the programme. The quality of student feedback has in some cases been denigrated to a popularity contest and it has also been suggested that the best evaluations arise from courses where students are not challenged too much (Arthur, 2009; Chan, Luk and Zeng, 2014; Stein et al, 2013). In other research Golding and Adam (2016) explain that HE teachers resist the need to alter their practice or do not understand what they need to do to improve. Where these problems exist the feedback from students is unlikely to lead to positive change.

Questionnaires scrutinising the method used to gather the information, focus group discussions and interviewing individuals have all been applied to discover HE teachers views of student evaluations (Arthur, 2009; Chan, Luk and Zeng, 2014; Stein et al, 2013). In a quantitative study that scrutinised responses to evaluations many teachers viewed the feedback as a threat and did not improve their teaching but instead made the course less challenging hoping to improve the results next time (Chan, Luk and Zeng 2014). In a study by Arthur (2009) HE teachers disclosed having an emotional reaction when reading student comments and scores which then inhibited a positive response. This suggests that the way that the HE teacher responds to student feedback is likely to shape the extent to which it leads to a positive outcome.

Other results show that HE teachers were positive about students' evaluations and Arthur (2009) concluded that the individual's self-efficacy and confidence was a significant determinant in this. Stein et al (2013) found that when the HE teacher respected students' opinions they were more willing to respond by making improvements to their practice. Golding and Adam (2016) recommend taking a reflective approach that invokes an 'improvement attitude' applying a student-centred solution. Others also report that a student-centred approach is a common feature in shaping a commitment to improve teaching (Hendry, Lyon 
and Henderson-Smart, 2007; McGowan and Graham, 2009). Reviewing the range of responses to student evaluations suggests that it would be useful to investigate the impact of introducing new approaches that capture student feedback.

\section{Story-telling}

Using stories as a communication tool has a long history characterised within fables, fairy tales and parables. Storylines provide structure as well as augmenting creative opportunities to explain information in curious and imaginative ways. Telling stories is described by Lambert (2010) as a different and less formal way to communicate. Labov (1972) reports two main functions within story-telling, the first enabling the writer to report what happened by referring to the experience and the second as an evaluative method of giving meaning to their narrative. The process of story-telling provides the opportunity to choose a personal context to convey information. The story writing process can be stimulating and motivational because the individual is given the opportunity to control how they describe the social construction of knowledge (Sharples et al 2014).

Bruner (2002, cited by Bolton, 2014, 70) explains 'Our stories impose a structure, a compelling reality on what we experience' that enable us to access and articulate what we know, think, believe, feel and remember. Writing the story and the result may therefore become bidirectional so that the writer 'makes their worlds knowable, not just to us and others but also to themselves' (Sherwood and Nind, 2014, 461). The construction of the story and sharing the contents offer the writer and reader a lens with which to identify and share experience.

\section{Methodology:}

O'Leary (2017) explains that accessing key informants leads to gathering their inside and expert knowledge. She suggests that the results enable the researcher to uncover what the participant has experienced and to review that experience from their perspective. In this study the students were key informants and taking an interpretive position when reading their 
stories meant that I could learn from their expert knowledge. As Davies and Hughes (2014) claim that this enables the researcher to construct a range of meanings that can be inferred from the literal content.

The forty-seven undergraduates who took part in this study came from three separate groups that I taught. Group one comprised of fifteen first year students, four males and nine females all studying either a BA in Childhood and Youth Studies or Early Childhood Studies. They each wrote a story during the final tutorial session of the year, providing feedback on their learning experiences looking back, reflecting on their learning experiences and what they meant for them going forward.

Group two included twenty female BA Early Childhood Studies third year students who in their final session of a module wrote composite stories in groups of five. They provided feedback on their learning experience focused on a single subject. The stories were recorded on flip chart sheets of paper using words and pictures.

The third group, from a different cohort of third year BA Early Childhood Studies wrote their stories half way through a module. The group comprised of ten female and two male undergraduates and each wrote a story about their learning experience from the lecture the previous week.

Each group received minimum direction so that they could decide on the message and style that they wanted to write in. I explained that it was not an assessment and that the content would be used to help me to improve my teaching. The lack of boundaries and detail could have potentially led to anxiety for some students but each individual and group engaged in the activity willingly and with enthusiasm.

For the purposes of anonymity and privacy the specific module titles are not used. Permission to share the content of their stories in a published paper was requested. All students were told 
that the paper would accurately represent their stories through the use of verbatim extracts and that any individual identifying features would be removed. Seeking informed consent, explanation of the right to withdraw, and the use of de-identified data for participants followed the ethical guidelines published by the British Education Research Association and was crucial to maintaining the bond of respect I had sought to establish with each of them. The procedure was shared and agreed by the university ethics committee. All forty-seven students agreed that their stories could be used.

In analysing the stories I applied content analysis and an interpretive reading of the data to identify core consistencies and meanings (Davies and Hughes, 2014; Patton, 2002). Data reduction and an iterative procedure of reading the stories and making notes led to identifying consistent themes. Following a method described by Silverman (2014) norms, orders, patterns, rules and structures were also detected. The themes from the stories identified the role of feelings, making connections with others, indicators of knowledge and changes over time. Extracts and interpretation from each group is shared in the next part of the paper.

\section{Findings}

\section{Stories written by first year students}

The stories analysed in this section were written by individual students who were looking back on their first year at university. I was surprised to find that eight of the fifteen students stories included negative emotions to describe how they felt when they first arrived. They used vocabulary such as 'sad, weird, worried, scared, feeling very homesick, struggle'. Two participants disclosed how their character had shaped the early days at university:

A shy girl decided to come to university, she was a very quiet individual and didn't know anybody else that was attending, But when she first went to her lecture she sat next to a girl that was in the same position and they became friends for life. 
A shy girl who suffered from anxiety and depression started her first day of uni. She found it hard to make friends. Over the last few months at university she managed to make a friend and this helped her to do work and have a social life.

These extracts showed me the significance of finding friends and making a social connection. As the second story shows this can be difficult and take time but when it is achieved it is transformative. Another female student added that although she was very nervous 'she met some nice friends and tutors and began getting good grades, she grew in confidence'. Research undertaken by Soria and Stubblefield (2015) endorse this explaining that when students become aware of their strengths and capabilities they are more likely to complete their studies successfully. These findings showed me aspects of the students' lives I may have otherwise missed and that responding to them could have an impact on student retention (Thomas, 2012).

One of the male participants presented his story using a traditional structure alongside a range of reflections that made the story appear very colourful:

Once upon a time in a land just off the ... A young, timid, attractive boy was moving to his new home, which many would describe as looking like a crack den. Time went by for this young, timid, attractive boy. He drank, he smiled, he made very good friends. This far away land off the ... had matured him. In his travels through this land he learnt how to do Tai Chi, how to shop for less than a tenner and how to use the least amount of petrol when picking up his friend who was too lazy to walk. His first year in this far away land off the ... was drawing to a close but his story does not end here he still has many years to come, this young, timid, attractive man.

Stories such as this illustrate the complexity of the university experience. This student describes life outside of the lectures and seminars and includes humour in the content. He reminded me that leisure pursuits play a significant role in the journey through undergraduate studies. As this student infers students are becoming increasingly adept at juggling competing 
priorities that involve multiple identities (Christie, Munro and Wager, 2005). My attention was initially drawn to aspects of the stories that were indicators of increased knowledge and yet those who included personal anecdotes became particularly informative. The students reminded me of the need to respect and identify with, rather than put aside these valuable experiences. Meehan and Howells (2018) longitudinal study of five hundred and thirty students also recommend that the HE teacher is aware of the range of needs of undergraduates in order to enhance their overall experience at university.

First year students showed how study can be both a concern and motivator: 'it was time for me to knuckle down and focus on what I was really here for ...essay after essay'; 'exam time is approaching, it's like a miracle I've managed to get myself organised...now I'm determined to do well as I 100\% now know this is what I want to do in the future and I don't want to fail again.' 'After the initial scariness of it all I began enjoying myself and enjoying the assignments'. These extracts show different interpretations of what assessment means to them. The style of their story gave me an insight into how they personalise the demands of academic rigour and its impact on their identity.

A central theme in all fifteen stories was change that led to examples of transformation:

First year daunting right? Of course. Mine was great. The university was so friendly, I felt so confident, I could do this. The course started talking about being there for children and giving them the attention they deserved. It started to feel like my own course told me I shouldn't be there. It was like grey clouds had covered the original sunshine. Grey clouds only get heavier and I started to wonder if my own child got the attention he craved. Grey clouds, eventually rain and my child said he loved me without me saying it first, it felt like the sun shone and that university only worked if everyone supports you. Now I know that there will be grey clouds after sun but everything is a cycle and sun will always shine after rain.

This student vividly communicates the nature of studying in the first year when you have the dual identity of undergraduate and parent. They showed me that developing resilience to 
manage challenges plays an important role within the university experience and that applying tools to manage difficult times makes a difference.

\section{Stories written by groups of third year students:}

Twenty students formed four groups to tell a story of their learning in the final session of a core module on practice in Early Years. They all produced stories on flip chart paper that included pictures with text. Three groups began with the phrase 'once upon a time', possibly because they equated the term story with a fairy tale. This interpretation was further endorsed when those groups concluded with 'happily ever after'.

The interesting and surprising aspect of one of the stories was how they experienced the opportunity to discover new knowledge and the emotions that this afforded:

Once upon a time there was an exhausted lady; she was exhausted but didn't know she was. One day she went for a long walk taking two leopard print bags, which she had packed with her most precious belongings.

Along the way she reached a crossroads where she found new, surprising inspiring objects. She longed to add them to her bags but had no room. Suddenly, she found herself in a situation; she had to make a choice. Does she continue on her path with her once most precious things or embrace the new surprising inspiring objects?

She poured the old things, no longer shiny and precious on the ground and scooped up the new inspiring objects placing them carefully in her bags. She confidently continued on the path excited by what she might find and who she might meet.

The use of figurative language applied in this story exposed the challenge closely of letting go of absolutes, making choices and embracing new ideas. The content matched my intention to disrupt and question aspects of professional practice that are often taken for granted. The results were in congruence with another group who drew a box accompanied by the words 
'now we think outside the box'. A further example from another group showed a picture with a series of curved lines annotated with 'Rainbow of positive possibility'.

Students also shared examples of new knowledge and skills they have gained such as; 'patience, leadership, commitment, organisation, planning' alongside 'we learnt to think critically and reflectively' which seemed to hold particular value to them. These terms were consistent with my intention to prepare this group for the work place by identifying links between learning and practice. However, reviewing this interpretation reminded me of the tendency to look for information that confirms what I hoped to find (Davies and Hughes, 2014).

There were aspects of the stories that I found jarring, particularly negative emotions, possibly because I could identify with personal feelings of uncertainty when learning something new. One group included pictures of tear streamed and anxious faces accompanied by a cloud. Yet, encountering and resolving challenges seems essential to growth and change. The requirement to accept uncertainty felt both real and uncomfortable as one group wrote 'to be continued... we hope for a happily ever after'. Alongside adversity each story contained optimism and celebration, perhaps due to group identity, a feature that is highly prized by university undergraduates (Meehan, 2011).

\section{Stories written by individual third year students}

The individual stories in this section reflected the learning from the previous week's lecture which twelve of the fifteen third year students had attended. This was a different cohort of undergraduates and linked to another core module that forms part of the Early Childhood degree. The lecture explored how the practitioner's use of language impacts on young children's learning. The link between story and fairy tale was evident as six students began their story with 'once upon a time' and two included a prince and princess as central characters: 
Once upon a time, in a classroom far away, a princess discovered the importance of the language she used with other princesses and princes, practising the sounds helped her understand the language she used and they all lived happily ever after.

Once upon a time, there lived a prince who was learning his alphabet. Many scholars tried and failed to teach the prince, who hated learning. But then the phonics fairy appeared and sprinkled her magic dust, teaching the boy phonics and he loved the fairy and her fairy dust and became the phonics prince.

These stories communicate how learning is empowering and suggest that it facilitates a positive identity. They also illustrate how others are instrumental in supporting learning, a theme that was applied by a further seven students. Sharing learning in a group was highlighted as important: 'this was discussed in class and we came to an agreement that children learn well through rhyme'. In this group there were examples of how positive emotions influence learning: 'I began to consider how language and intonation is used in storytelling, how repetition helps children to become excited in their knowledge of the story'. Others shared their personal emotions for example 'I left with a greater knowledge and felt good for the rest of the day'; 'the student enjoyed this lecture very much and thought about it all the way home.' Two other students explained how they had talked about it together as they walked home.

The stories that emerged from this activity were shorter than those written by the other two groups. The reason may have been the specificity of the requested feedback as they had to recall the previous week's session. They may have interpreted the request as a memory test rather than an evaluation of the learning experience, or it is possible that they were confused by the sudden introduction of writing a story and were unsure about how to go about it. Although there were limitations to the stories, the results encouraged me to consider the impact of my teaching and how to enrich it in future. 


\section{Discussion:}

The purpose of analysing student's stories was to find out information that could enhance pedagogy. The stories written by students reveal an important connection between increments in knowledge and managing emotions. Effective practice in teaching therefore needs to reflect this dynamic. Meehan and Howells (2018) recommend building strong connections between undergraduates and academic staff through small class activities. This involves merging the practice of transferring knowledge with developing relationships with students (Arthur, 2009; Dunworth and Santiago Sanchez 2016; Surgenor, 2013). The aim would be to adopt a pedagogy that is open and friendly, that encourages collaborative co-learning inviting a candid exchange of ideas, openness, dialogue and debate (Golubchikov, 2015).

Students' stories recognise the importance of being successful at university and the NSS and SET surveys often report that assessment receives the lowest score (Lenton, 2015). Analysis of the stories showed that students did not refer to any of the literature that is necessary to demonstrate their core knowledge and understanding. To develop the content of students' assessments, opportunities for engagement and debate using literature creatively to broaden students' awareness and deepen their interest are important (Arthur, 2009; Jenkins, Jones and Ward, 2001). The intended outcome is to improve their confidence and engagement in the assessment process.

The stories show how confidence plays an important role in successfully completing assessments. Activities such as opportunities for formative feedback that involves peer assessment are designed to address this (Carless, 2015). This practice introduces social constructivism (where students construct new knowledge together) extending their understanding of the subject (O'Donovan, Price and Rust 2008). The aim is to motivate, engage and inspire students as they compare alternative views and explanations of theory and 
practice as well as different interpretations and applications (Woodward-Kron, 2002). These plans are intended to benefit the students by widening their experience and skills.

Cooper (2000) asked students to write stories about their views of assessment to encourage reflection and to move beyond simply considering what they need to do to pass. In this research student stories showed that improving their confidence and resilience is likely to support their attainment (Jenkins, Jones and Ward, 2001). Analysis and interpretation of these stories has led to interweaving teaching and assessment in a student-centred way.

The content of student stories illustrates knowledge that is commensurate with requirements in the work place. Since the 1980s reports and papers from government, industry and HE practitioners have urged universities to ensure that transferable and employability skills are embedded in students' learning experiences (e.g. Atkins, 1999, CBI, 2015, and Dearing, 1997). Success in supporting students into employment is one of the performance measures captured in the Destination of Leavers from Higher Education (DHLE). This aspect of pedagogy is therefore important to develop.

Analysis of students' stories in this research reminds the HE teacher that activities such as coaching and mentoring within peer groups and across the different year groups are useful and promote transferable skills. Peer to peer interview activities where the students share experiences introduces them to new ideas and confidence in developing communication skills that are a crucial gateway to the labour market (Dickerson, Jarvis and Stockwell, 2016; Jenkins, Jones and Ward 2001).

\section{Conclusion:}

The findings within this research recommend a different method to gather student feedback on their learning experience but story-telling does not suggest that it provides all the answers. Information can remain hidden for a variety of reasons; for example, the individual may lack 
confidence in sharing their views or fear that there will be consequences if they share any negative observations (Khan, 2013; Golubchikov, 2015). This research does not claim that every HE teacher would find this type of evaluation useful or easy to respond to, as research indicates there are a variety of barriers that hinder the enhancement of pedagogic practice (Arthur, 2009; Cooper, 2000; Golding and Adam, 2016; Winchester and Winchester, 2013). Yet, as Stein et al (2013) explain there are flaws to every system of evaluation and new methods need to be tried so that $\mathrm{HE}$ teachers can engage in understanding students' learning experiences.

This research shows that when students write their own story they provide an evaluation of the learning experience in a more nuanced way. The results therefore help to deflect the direct judgement implied via the ratings of analysed Likert scales and found to have a negative impact on some of the participants in Arthur's (2009) research. In the same way that HE teachers' feedback to students can be described as 'complex, multifaceted and mediated by numerous contextual variables' (Dunworth and Santiago Sanchez, 2016, 1) so it is with their feedback to us.

Ultimately the purpose of gathering feedback is to benefit student outcomes and address their needs. These needs go beyond gathering new knowledge to 'gains in confidence, critical thinking, a broadening awareness and a deepening interest' (Jenkins et al, 2001, 150). When Evans (2013) reviewed the literature on assessment she concluded that we need to continue to consider the relationship between emotions and cognition, contextual variables and how these may be addressed, developing students' ability to both use and give feedback. In practice and in research it is important to embrace the views of students and learn different ways to incorporate their voice in shaping the future of education.

This research began with an interest in the subject of evaluation and how current methods that are gathered in NSS and SET surveys are limited in the information they contain. The use 
of SET surveys and the NSS data enabled me to locate gaps in my knowledge and listening to students through story-telling became a method to find out what I was missing. The three groups of students whose stories are contained in this research chose to blend their learning and how this was accomplished in their own words using a structure developed independently of specific guidelines. Their contributions meant that I had a clearer understanding of what had worked well in my teaching and how this could be enhanced in future.

The research explains how story-telling contributes to the current discourse of responding to student feedback. The central remit of story-telling is to listen to voices we do not normally hear (Flint et al, 2009). My focus was primarily on teaching and the wellbeing of students. Others may apply different criteria. Although the students responded positively this may not apply to those studying in other subject disciplines. It is possible that some students may be confused by the idea of telling a story about their learning, unsure of its purpose and uncomfortable. However, story-telling is something that Shaples et al (2014) recommend is applied beyond the arts subjects due to the creative opportunities it offers. Where students are unfamiliar or reticent to try story-telling, finding ways to be flexible, involving them in solutions such as offering greater anonymity or perhaps using the university's virtual learning environment, journals, film or audio may be helpful (Carless, 2015; Moon, 2014; Winchester and Winchester, 2014).

This paper recommends further research, particularly in capturing students' views on storytelling. Although the NSS and SET surveys have and continue to provide useful and easily analysed snapshots of the student evaluation of learning, a wider range of options for capturing qualitative information is recommended by research cited in this paper. Asking students to write stories about their learning is likely to produce different information than is currently captured on student surveys. In this research I found that story-telling provided me 
with an insight into the minds of students who communicated information about their learning experiences that I might otherwise have been missed and overlooked.

\section{References}

Arthur, L. 2009. 'From performativity to professionalism: lecturers' responses to student feedback." Teaching in Higher education. 14 (4): 441-454. doi:10.1080/13562510903050228.

Ashwin, P. (2017). Making sense of the teaching excellence framework (TEF) results. Times Higher Education. Retrieved August 2, 2017, from: www.timeshighereducation.com.

Atkins, M.J. 1999. "Oven-ready and Self-basing: taking stock of employability skills." Teaching in Higher Education. 4 (2): 267-280. doi:10.1080/1356251990040208.

Bolton, G. 2014. Reflective Practice: Writing and Professional Development. 4th ed. London: Sage.

Callender, C. P. Ramsden and Griggs, J. 2014. Review of the National Student Survey. London: HEFCE.

Carless, D. 2015. "Exploring learning-orientated assessment procedures.” Higher Education 69: 963-976. doi: 10.1007/s10734-014-9816-z.

Chan, C.K.Y., L.Y.Y. Luk., and M, Zeng. 2014. “Teachers' perceptions of student evaluations of teaching." Education Research and Evaluation: An International Journal of Theory and Practice. 20 (4): 275-289. doi:10.1080/13803611.2014.932698. 
Cooper, N.J. 2000. Facilitating Learning from Formative Feedback in Level 3 Assessment. Assessment and Evaluation in Higher Education 25, (3): 279-291. doi: 10.1080/02602930050135149.

Confederation of British Industry (CBI). 2015. Inspiring growth: CBI/Pearson Education and Skills Survey 2015. London: Pearson.

Christie, H., M. Munro., and F. Wager. 2005. "Day Students' in Higher Education: Widening Access Students and Successful Transitions to University Life.” International Studies in Sociology of Education. 15 (1): 3-30.

Curtin, B. 2013. Development of a student evaluation quality culture: the eVALUate experience at Curtin University. Enhancing Student Feedback and Improvement Systems in Tertiary Education, 16-33. CAA quality Series 5. Abu Dhabi, UAE: Commission for Academic Accreditation (CAA).

Davies, M., and N. Hughes. 2014. Doing a Successful Research Project: Using Qualitative or Quantitative Methods. $2^{\text {nd }}$ ed. London: Palgrave Macmillan.

Dearing, R. 1997. Higher Education in the Learning Society. National Committee of Inquiry into Higher Education, Summary Report NCIHE/97/849. London: HMSO.

Dickerson, C., J. Jarvis., and L. Stockwell. 2016. "Staff-student collaboration: student learning from working together to enhance educational practice in higher education." Teaching in Higher Education. 21 (3): 249-265. doi:10.1080/13562517.2015.1136279.

Dunworth, K., and H. Santiao Sanchez. 2016. "Perceptions of quality in staff-student written feedback in higher education: a case study." Teaching in Higher Education. doi:10.1080/13562617.2016.1160219.

Evans, C. 2013. "Making Sense of Assessment Feedback in Higher Education." Review of Educational Research. 83 (1): 70-120. doi:10.3102/0034654312474350. 
Flint, A., A. Oxley., P. Helm., and S. Bradley. 2009. "Preparing for success: one institution's aspirational and student focused response to the National Student Survey." Teaching in Higher Education. 14 (6): 607-618. doi:10.1080/13562510903315035.

Golding, C., and Adam, L. 2016. "Evaluate to improve: useful approaches to student evaluation." Assessment \& Evaluation in Higher Education. 41 (1): 1-14. doi:10.1080/02602938.2014.976810.

Golubchikov, O. 2015. "Negotiating critical geographies through a "feel-trip": experiential, affective and critical learning in engaged fieldwork. Journal of Geography in Higher Education. 39 (1): 143-157. doi: 10.1080/03098265.2014.1003800.

Grebennikov, L., and M. Shah. 2013. "Student voice: using qualitative feedback from students to enhance their university experience." Teaching in Higher Education. 18, (6): 606-618. doi: 10.1080/13562517.2013.774353.

Hendry, G.D., P.M. Lyon., and C. Henderson-Smart. 2007. “Teachers' Approaches to Teaching and Responses to Student Evaluation in a Problem-based Medical Program." Assessment and Evaluation in Higher Education. 32 (2): 143-157. doi:10.1080/02602930600801894.

Hoon, A., E. Oliver., K. Szpakowska., and P. Newton. 2015. "Use of the 'Stop, Start, Continue' method is associated with the production of constructive qualitative feedback by students in higher education." Assessment and Evaluation in Higher Education. 40, (5): 755-767. doi: 10.1080/02602938.2014.956282.

Jenkins, A., L. Jones., and A. Ward. 2001. “The Long-term Effect of a Degree on Graduate Lives." Studies in Higher Education. 26 (2): 147-161. Doi:10.1080/03075070124527. 
Khan, M. 2013. "Evaluation of Course Evaluations: Views from Students, Staff and Senior Management: Enhancing Student Feedback and Improvement Systems in Tertiary Education.” CAA Quality Series (5): 112-123.

Labov, W. 1972. Language in the Inner City: Studies in the Black English Vernacular. Philadelphia, PA: University of Pennsylvania Press.

Lambert, J. 2013. Digital Storytelling: Capturing Lives, Creating Community. $4^{\text {th }}$ ed. Abingdon: Routledge.

Lenton, P. 2015. "Determining student satisfaction: An economic analysis of the National Student Survey.” Economics of Education Review. 47: 118-127. doi: 10.1016/j.econedurev.2015.05.001.

Meehan, C. 2011. "Belonging, Being and Becoming: The Importance of Understanding Beliefs and Practices in the Teaching of Religious Education in the Early Years. Journal of Religious Education. 59 (3): 36-49.

Meehan, C., and K. Howells. 2018. "In search of the feeling of 'belonging' in higher education: undergraduate students transition into higher education." Journal of Further and Higher Education. 1-15. doi:10.1080/0309877X.2018.1490702.

Moon, J. 2014. Resources for storytelling. London: HEFCE.

McGowan, W.R., and C.R. Graham. 2009. "Factors Contributing to Improved Teaching Performance." Innovative Higher Education. ” 34 (3): 161-171. doi: 10.1007/s10755-009-1903-6.

O’Donovan, B., M. Price., and Rust, C. 2008. "Developing student understanding of assessment standards: a nested hierarchy of approaches." Teaching in Higher Education. 13 (2): 205-217. doi:10.1080/13562510801923344.

O’Leary, Z. 2017. The Essential Guide to Doing Your Research Project. $3^{\text {rd }}$ ed. London: Sage. 
Patton, M.Q. 2002. Qualitative Research and Evaluation Methods. $3^{\text {rd }}$ ed. Thousand Oaks, CA: Sage.

Sharples, M., A. Adam., R. Ferguson., M. Gave., P. McAndre., B. Rienties., M. Weller., and D. Whitelock. 2014. Innovating Pedagogy 2014: Open University Innovation Report 3.

Milton Keynes: The Open University.

Sherwood, G., and M.A. Nind. (2014). 'Parents' experiences of support: coconstructing their stories.” International Journal of Early Years Education. 22 (4): 457-470. doi.org/10.1080/09669760.2014.970520

Silverman, D. 2014. Interpreting Qualitative Data. 5th ed. London: Sage.

Stein, S.J., D. Spiller, S.Terry., T. Harris., L. Deaker., and J. Kennedy. 2013. “Tertiary teachers and student evaluations: never the twain shall meet?" Assessment and Evaluation in Higher Education. 38 (7): 892-904. doi:10.1080/02602938.2013.767876.

Surgenor, P.W.G. 2013. "Obstacles and opportunities: Addressing the growing pains of summative student evaluation on teaching." Assessment and Evaluation in Higher Education, 38 (3): 363-376. doi: 1080/02602938.2011.635247.

Symons, R. 2006. "In Their Own Words: Finding out What Students Think About Their University Learning Experience.” Synergy. 23: 34-35. http://trove.nla.gov.au/work/153072206?versionID $=166823830$

Thomas, L. 2012. Building Student Engagement and Belonging in Higher Education at a Time of Change: Final Report from the What Works? Student Retention and Success Programme. London: HEFCE. 
Times Higher Education. 2017. Times Higher Education Student Experience Survey. https://www.timeshighereducation.com/student/news/student-experience$\underline{\text { survey-2017-results. }}$

Soria, K., and R. Stubblefield. 2015. "Knowing Me, Knowing You: Building Strengths Awareness, Belonging and Persistence in Higher Education.” Journal of College, Student Retention: Research, Theory and Practice. 1-22. doi:10.1177/1521025115575914.

Winchester, T.M., and M. K. Winchester. 2014. "A longitudinal investigation of the impact of faculty reflective practices on students' evaluations of teaching." British Journal of Educational Technology. 45 (1): 112-124. doi:10.1111/bjet.12019.

Woodward-Kron, R. 2002. "Critical analysis versus description? Examining the relationship in successful student writing." Journal of English for Academic Purposes. 1 (2): 121-143. 